\title{
Detection of the GPI-anchorless prion protein fragment PrP226* in human brain
}

\author{
Eva Dvorakova ${ }^{1 \dagger}$, Tanja Vranac ${ }^{2 \dagger}$, Olga Janouskova ${ }^{1,4}$, Maja Černilec $^{2}$, Simon Koren², ${ }^{2,}$ Anja Lukan², Jana Nováková ${ }^{3}$,
} Radoslav Matej ${ }^{3}$, Karel Holada ${ }^{1}$ and Vladka Čurin Šerbec ${ }^{2^{*}}$

\begin{abstract}
Background: The accumulation of the misfolded forms of cellular prion protein, i.e. prions $\left(\operatorname{PrP}^{\mathrm{Sc}}\right)$, in the brain is one of the crucial characteristics of fatal neurodegenerative disorders, called transmissible spongiform encephalopathies (TSEs). Cellular prion protein is normally linked to the cell surface by the glycosylphosphatidylinositol (GPI) anchor. There is accumulating evidence that the GPI-anchorless prion protein may act as an accelerator of formation and propagation of prions. In the TSE affected human brain we have previously discovered a novel GPI-anchorless prion protein fragment, named PrP226*, which ends with the tyrosine 226. This fragment can be labeled specifically by the monoclonal antibody V5B2.
\end{abstract}

Methods: We developed a DELFIA based assay for quick and sensitive detection of the PrP226* fragment in human brain tissue homogenates. By calculating the ratio between the signals of native (N) and denatured (D) samples applied to the assay we were able to observe significant difference between 24 TSE affected brains and 10 control brains. The presence of PrP226* in brain tissue was confirmed by western blot.

Results: Our results demonstrate that PrP226* is present in small quantities in healthy human brain, whereas in degenerated brain it accumulates in prion aggregates, proportionally to $\mathrm{PrP}^{\mathrm{Sc}}$. Samples with high D/N ratio generally comprised more proteinase $\mathrm{K}$ resistant $\mathrm{Pr} P$, while no correlation was found between the quantity of PrP226* and standard classification of Creutzfeldt-Jakob disease (CJD).

Conclusions: In the present study we show that the PrP226* fragment accumulates in prion aggregates and after being released from them by a denaturation procedure, could serve as a proteinase $\mathrm{K}$ digestion independent biomarker for human TSEs. The PrP226* assay described in this paper offers a tool to follow and study this unique anchorless PrP fragment in various parts of human brain and possibly also in other tissues and body fluids.

Keywords: Transmissible spongiform encephalopathies, Creutzfeldt-Jakob disease, GSS, Prion, V5B2, Immunoassay, DELFIA, Anchorless PrP, PrP fragment, Proteinase K

\section{Background}

Transmissible spongiform encephalopathies (TSEs), or prion diseases, are phenotypically heterogeneous group of fatal neurodegenerative disorders of humans and animals. Human prion diseases include Creutzfeldt-Jakob disease (CJD), kuru, Gerstmann-Sträussler-Scheinker disease (GSS) and Fatal familial insomnia. Prion diseases can be sporadic (i.e. spontaneous, $85 \%$ ), familial (i.e. inherited, $10-15 \%)$ or acquired (i.e. transmitted by infection, $2-3 \%$ ).

\footnotetext{
*Correspondence: vladka.curin@ztm.si

${ }^{\dagger}$ Equal contributors

${ }^{2}$ Department for Production of Diagnostic Reagents and Research, Blood

Transfusion Centre of Slovenia, Šlajmerjeva 6, 1000 Ljubljana, Slovenia

Full list of author information is available at the end of the article
}

Prion diseases are characterized by misfolding of the normal cellular prion protein $\left(\operatorname{PrP}^{\mathrm{C}}\right)$ into the pathological isoform $\left(\mathrm{PrP}^{\mathrm{Sc}}\right)$ [1]. Conversion into abnormal $\mathrm{PrP}^{\mathrm{Sc}}$ is associated with an increase in $\beta$-sheet secondary structure and aggregation of the protein $[2,3]$. As a result, $\mathrm{PrP}^{\mathrm{Sc}}$ is insoluble in non-denaturing detergents and partially resistant to protease digestion. Diagnostic methods are mostly based on the treatment of samples with proteinase $\mathrm{K}(\mathrm{PK})$ which degrades $\operatorname{PrP}^{\mathrm{C}}$, while the resistant fragment of pathological prion protein (PrPres) can be detected with anti-PrP antibodies. 
Molecular strain typing of human prion diseases has focused mainly on differences in the PrPres size and glycosylation site occupancy in conjunction with the presence of mutations and polymorphisms in the prion protein gene $(P R N P)$. Based on differences in gel mobility and N-terminal sequence of the core fragments (PrP27-30) generated by PK digestion, Parchi et al. originally identified two major human $\mathrm{PrP}^{\mathrm{Sc}}$ types in human prion diseases: type 1 having a relative molecular mass $21 \mathrm{kDa}$ of nonglycosylated PrPres with the primary cleavage site at residue 82 and type 2 having a relative molecular mass $19 \mathrm{kDa}$ with the primary cleavage site at residue $97[4,5]$. The two $\mathrm{PrP}^{\mathrm{Sc}}$ types in conjunction with PRNP gene polymorphism at codon 129 , that encodes either methionine (Met) or valine (Val), provided for the first time a molecular basis for disease classification [6]. An alternative classification has been suggested by Collinge et al. $[7,8]$. In GSS, two different pathological phenotypes are associated either with type 1 PrPres or with a 7-kDa to 8-kDa PrPres fragment [9].

As the research in the field of prion biology advanced, the evidence of the physicochemical heterogeneity of $\mathrm{PrP}^{\mathrm{Sc}}$ in human and animal prion diseases accumulated [9-13]. The classical typing thus became insufficient for understanding the complex coexistence of distinct structural conformers of $\mathrm{PrP}^{\mathrm{Sc}}$ in prion diseases formation and progression.

The reports on various truncated forms of the abnormal protein are also in accordance with the structural diversity of the $\operatorname{PrP}^{\mathrm{Sc}}$. One of the identified $\operatorname{PrP}$ fragments is the glycosylphosphatidylinositol (GPI)-anchorless $\operatorname{PrP}$, truncated at the very $C$ terminus [13-15]. Although the role of the GPI anchor in $\mathrm{PrP}^{\mathrm{Sc}}$ replication and disease propagation remains unclear [16-18], there is increasing evidence on GPI-anchorless PrP, i.e. PrP $(\triangle \mathrm{GPI})$, acting as an accelerator of formation and propagation of prions. Heterozygous transgenic mice lacking the sequence for GPI-anchor on one of the PrP alleles, developed clinical signs and died faster than the wildtype mice upon the TSE infection, while their brains appeared to have PrPres generated from both, GPIanchored and anchorless PrP forms [19]. Stöhr et al. reported recently that mice overexpressing PrP $\Delta$ GPI developed a spontaneous neurological disease [20]. A similar situation was described in human patients with stop codon mutations at the codons 226 and 227, resulting in the formation of C-terminally truncated PrP, ending either with tyrosine 225 or with tyrosine 226 , respectively. Both patients were heterozygous, with the second allele coding for normal PrP, and displayed atypical prion protein amyloidoses [21]. GPI-anchorless PrP was also found on blood cells of patients with paroxysmal nocturnal hemoglobinuria suffering from the clonal defect in GPI synthesis [22,23]. However, in their affected cells the protein seems to be expressed intracellularly, likely in a transmembrane form [23] and patients do not exhibit neurological symptoms.

We previously described development and characteristics of the monoclonal antibody V5B2, raised against human PrP peptide 214-226 [24]. V5B2 specifically recognizes $\mathrm{C}$-terminally truncated fragment of the prion protein that ends with the residue Y226, which was named PrP226* [25]. V5B2 thus represents a unique tool to study localization and behavior of this GPI-anchorless PrP fragment in different biological samples. In this study we developed a V5B2 based sandwich DELFIA immunoassay for detection of the fragment PrP226* in human brain homogenates. Our method is based on comparison of the quantity of $\operatorname{PrP} 226^{*}$, measured in native and denatured samples. Its principle is similar to the Conformation-Dependent Immunoassay, reported by Safar et al. [26]. We tested 20 sCJD, 3 fCJD, 1 GSS and 10 non-CJD brain homogenates and we found that the fragment PrP226* accumulates in TSE affected brain, most abundantly in the GSS case. The amount of PrP226* was generally proportional to the amount of $\mathrm{PrP}^{\mathrm{Sc}}$ and PrPres in prion aggregates.

\section{Results}

\section{PrP226* C-terminus is degraded by PK}

Western blot analyses of SCJD and non-CJD brain homogenates were performed with two anti-PrP mAbs, $6 \mathrm{H} 4$, that reacts with the epitope PrP144-152 and V5B2, that reacts with the epitope PrP214-226, with last three amino acids AYY being crucial for binding (Figure 1A). It has been shown before that AYY must be freely exposed; a single amino acid addition to the C-terminus of this epitope completely abolishes V5B2 binding. Therefore V5B2 is specific for the PrP fragment that ends with 226, i.e. PrP226* [25]. PrP226* is barely visible in nonCJD brain, but is present in substantial amounts in human sCJD brain homogenates in all three glycoforms. In contrast, signals of similar intensity were obtained for both SCJD and non-CJD samples when using 6H4 for the immunodetection. PrP226* migrates a few $\mathrm{kDa}$ faster than the whole PrP (Figure 1B). PK digestion of samples resulted in PrPres, detected with $\mathrm{mAb} 6 \mathrm{H} 4$, while the V5B2 epitope on PrP226* was largely degraded (Figure $1 \mathrm{C}$ ).

\section{Optimization of denaturation conditions for the immunoassay}

We have previously detected PrP226* in $\operatorname{PrP}^{\mathrm{Sc}}$ deposits in the brain of SCJD patients by immunohistochemistry (IHC) [24]. Therefore, in order to be able to detect the PrP226*, packed in prion aggregates, we set a denaturation protocol for brain homogenates. We first optimized denaturation of samples by Gdn-SCN in a V5B2/ 


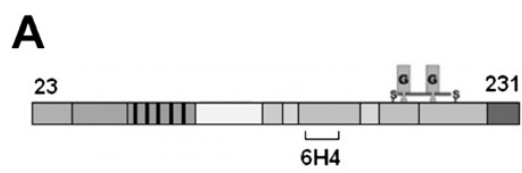

B

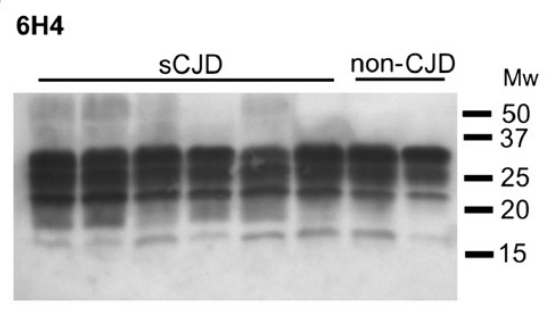

$\mathrm{C}_{6 \mathrm{H} 4}$

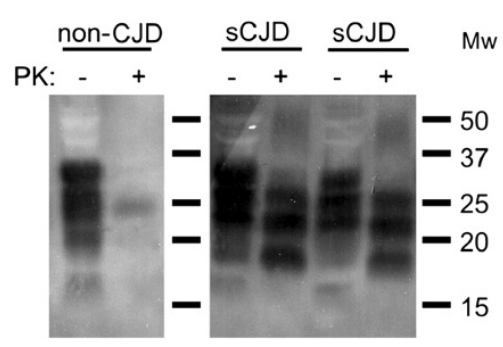

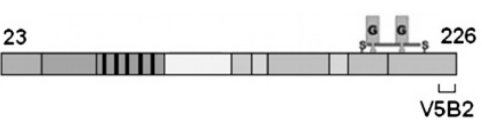

V5B2
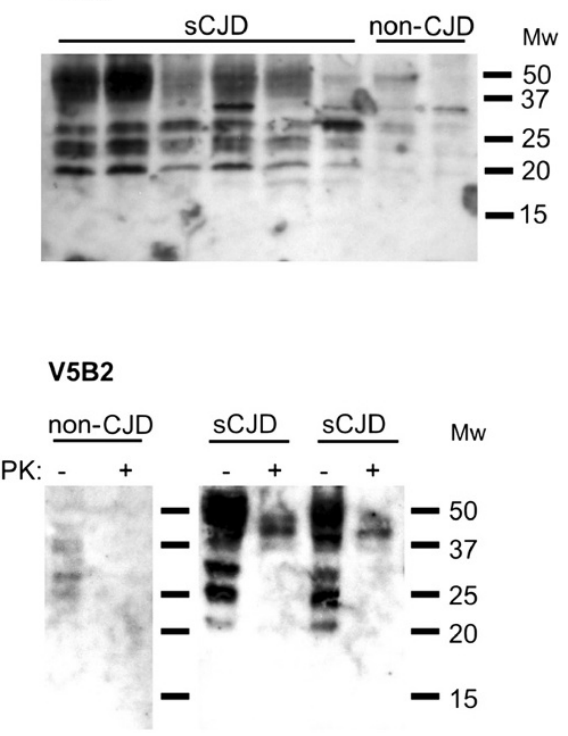

Figure 1 Western analysis of human brain homogenates. (A) Epitopes of mAbs $6 \mathrm{H} 4$ and V5B2, which were used for immunodetection. (B) Analysis of six SCJD and two non-CJD brain homogenates without PK treatment. (C) The effect of PK digestion on the immunodetection with mAbs $6 \mathrm{H} 4$ and $\mathrm{V} 5 \mathrm{~B} 2$.

EM20-b sandwich ELISA. Two SCJD brain homogenates were treated with increasing concentration of Gdn-SCN at $60^{\circ} \mathrm{C}$ for $15 \mathrm{~min}$ (Figure $2 \mathrm{~A}$ ). When the concentration of Gdn-SCN, to which the samples were exposed, was higher than $1 \mathrm{M}$, we noticed a substantial decrease of the signal, which could be at least partially attributed to the denaturation of the capturing antibody and thus reducing its binding capacity (Figure 2A). In order to study this effect of Gdn-SCN, we mixed recombinant $\mathrm{PrP}_{22} 6^{*}$ (recPrP226*, at the concentration $10 \mu \mathrm{g} / \mathrm{ml}$ ) with $3 \mathrm{M}$ Gdn-SCN, volume ratio 1:1. The mixture was then serially diluted and loaded to the wells of the microtiter plate. The highest signal was obtained at the concentration of $0.075 \mathrm{M}$ Gdn-SCN (Figure 2B). In
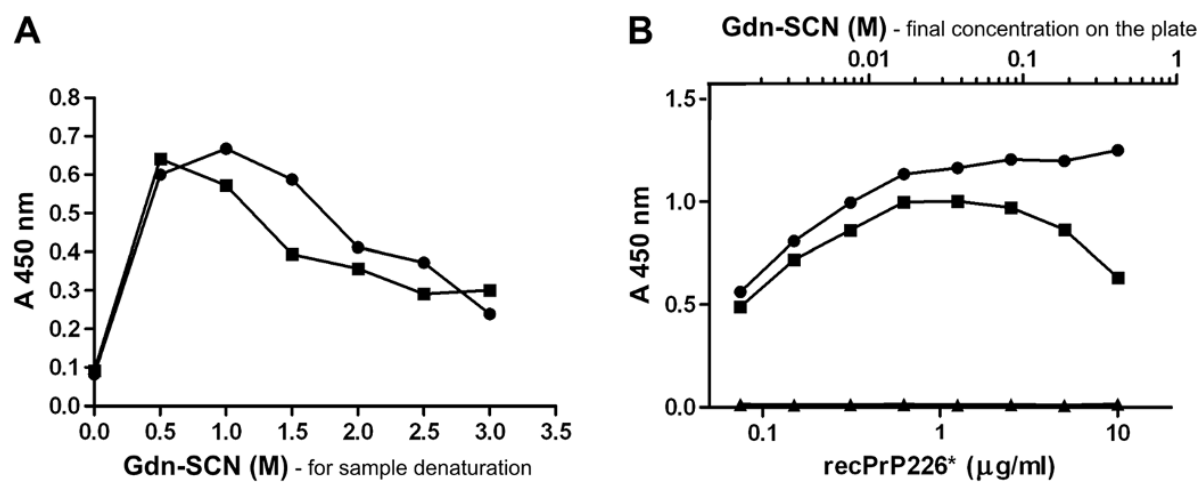

Figure 2 Determination of the optimal Gdn-SCN concentration for denaturation of samples. (A) Two 10\% SCJD brain homogenates ( and $\bullet$ ) were treated with increasing concentration of Gdn-SCN (0-3 M). Samples were 10 times diluted and the fragment PrP226* was measured by V5B2/EM20-b sandwich ELISA. (B) The effect of Gdn-SCN on the capturing antibody V5B2 was determined using rec PrP226* which

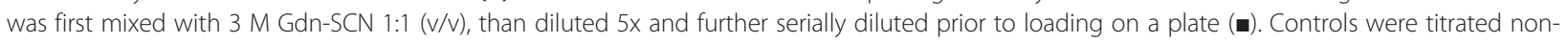
denatured recombinant $\operatorname{PrP} 226^{*}(\bullet)$ and $\operatorname{PBS}(\mathbf{\Delta})$. 
further experiments, $3 \mathrm{M}$ Gdn-SCN was added to the $10 \%$ brain homogenates (vol 1:1). Samples were incubated for $15 \mathrm{~min}$ at $60^{\circ} \mathrm{C}$ and then further diluted $20 \times$ to a final concentration of $0.25 \%$ brain homogenate in 0.075 M Gdn-SCN.

\section{PrP226* assay}

The determined denaturing and non-denaturing conditions were used to measure the signal of PrP226* in
23 CJD, 1 GSS and 10 non-CJD brain homogenates by sandwich DELFIA. In CJD/GSS samples, the signal at denaturing conditions was usually higher than in nondenaturing conditions (Figure 3A and $\mathrm{C}$ ), whereas in nonCJD samples, the signal decreased after denaturation (Figure 3B and D). Although this phenomenon was always observed, the measurements of the same samples differed significantly between experiments, due to the sensitivity of DELFIA to slight variations in the

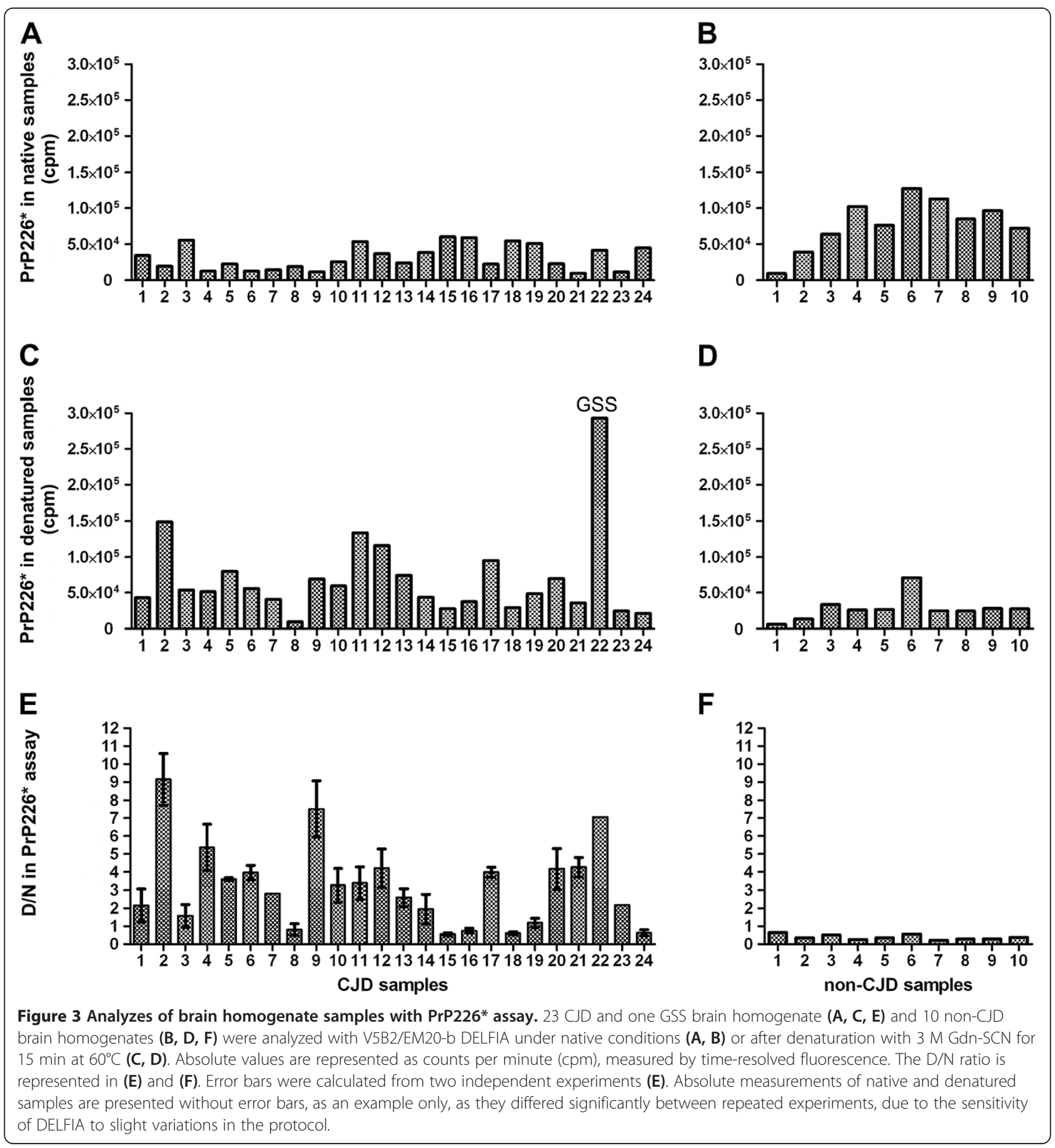


protocol. The differentiation between CJD and nonCJD as well as the repeatability of the assay was significantly improved after applying the ratio between the signal of denatured samples and the signal of native samples $(\mathrm{D} / \mathrm{N},[26]) . \mathrm{D} / \mathrm{N}$ values of all 10 non-CJD samples were $\leq 0.65$ (Figure 3F). CJD/GSS samples formed two groups, the first with $\mathrm{D} / \mathrm{N}$ ratios between 0.55 and 1.58 (samples $3,8,15,16,18,19$ and 24), and the second with $\mathrm{D} / \mathrm{N}$ ratios $\geq 2.0$ (all other CJD/GSS samples, Figure 3E).

To investigate whether the low $\mathrm{D} / \mathrm{N}$ values of the first group of CJD/GSS samples were caused by insufficient homogenization or denaturation of the samples, we repeated the measurements of these samples after additional homogenization by passage through the insulin syringe with $31 \mathrm{G}$ needle and by their denaturation at higher temperature (ie. by $1.5 \mathrm{M}$ Gdn-SCN for $10 \mathrm{~min}$ at $90^{\circ} \mathrm{C}$ ). However, the treatment did not lead to the change of $\mathrm{D} / \mathrm{N}$ values of these samples (data not shown).

We proved that $\mathrm{D} / \mathrm{N}$ correlates with $\mathrm{D}$ values alone, i.e. with the concentration of PrP226*, detected after the denaturation of samples (Additional file 1).

\section{Stability of the fragment PrP226* in human brain homogenates}

The stability of $\mathrm{PrP} 226^{*}$ fragment was determined by V5B2/EM20-b ELISA in the immediately frozen aliquot and the duplicate left overnight at RT. We observed that in average $94.3 \%( \pm \mathrm{SD} 14.1 \%)$ of $\mathrm{PrP} 226^{*}$ remained in non-CJD and $99.2 \%( \pm$ SD $16.9 \%)$ of PrP226* in sCJD brain homogenates (Figure 4A). Additional experiment was performed by spiking recombinant PrP226* into the non-CJD brain homogenate, which was stored at $4^{\circ} \mathrm{C}$, at $\mathrm{RT}$ or at $37^{\circ} \mathrm{C}$. Aliquots, taken at three time points, were examined by western blot. The densitometry analyses showed that, compared to the control recPrP226*
(Figure 4B, line 10), the spiked recPrP226* was degraded for $25 \%$ at the most, in the aliquot that was left for two hours at RT (Figure 4B).

\section{Correlation of PrP226* assay with CDI}

The results from PrP226* assay were compared to CDI, applied to similar denaturation conditions as were used for the PrP226* assay, with the sole exception that guanidine hydrochloride $(\mathrm{Gdn}-\mathrm{HCl})$ was used instead of Gdn-SCN. CDI assay, described by Safar et al. [26], depends on the effect of increasing concentrations of Gdn$\mathrm{HCl}$ to unmask epitopes in $\operatorname{PrP}^{\mathrm{Sc}}$ that become hidden during the structural rearrangements involved in the formation of $\mathrm{PrP}^{\mathrm{Sc}}$ and its deposits. In our setting, samples exposed to $4 \mathrm{M}$ Gdn- $\mathrm{HCl}$ were detected in a FH11/3F4-b sandwich DELFIA and D/N values were obtained for all CJD/GSS samples (except the sample 20, which was no more available, Figure 5A) and all of the non-CJD samples (not shown). The cut-off $\mathrm{D} / \mathrm{N}$ value between CJD/GSS and non-CJD measured with CDI was determined to be 1.0. The statistical correlation between the $\mathrm{D} / \mathrm{N}$ values of CJD/GSS samples measured by V5B2/EM20-b DELFIA and the $\mathrm{D} / \mathrm{N}$ values of the same samples, measured by CDI by FH11/3F4-b DELFIA (Figure 5B), proved to be highly significant ( $\mathrm{P}$ value 0.0005 and Pearson correlation factor $r=0.6673$ ) when evaluating all 23 values. These data indicate that the amount of PrP226* in CJD/GSS brain homogenates is proportional to the total amount of misfolded $\mathrm{PrP}^{\mathrm{Sc}}$ in them.

\section{PrP226* correlation with PrPres}

Next we evaluated the correlation between the PrP226* $\mathrm{D} / \mathrm{N}$ values and the PK resistance of samples. For this purpose we chose 12 out of 24 CJD/GSS samples which were outstanding due to their very low or very high $\mathrm{D} / \mathrm{N}$ ratio. Western blot analyses performed with $\mathrm{mAb} 3 \mathrm{~F} 4$

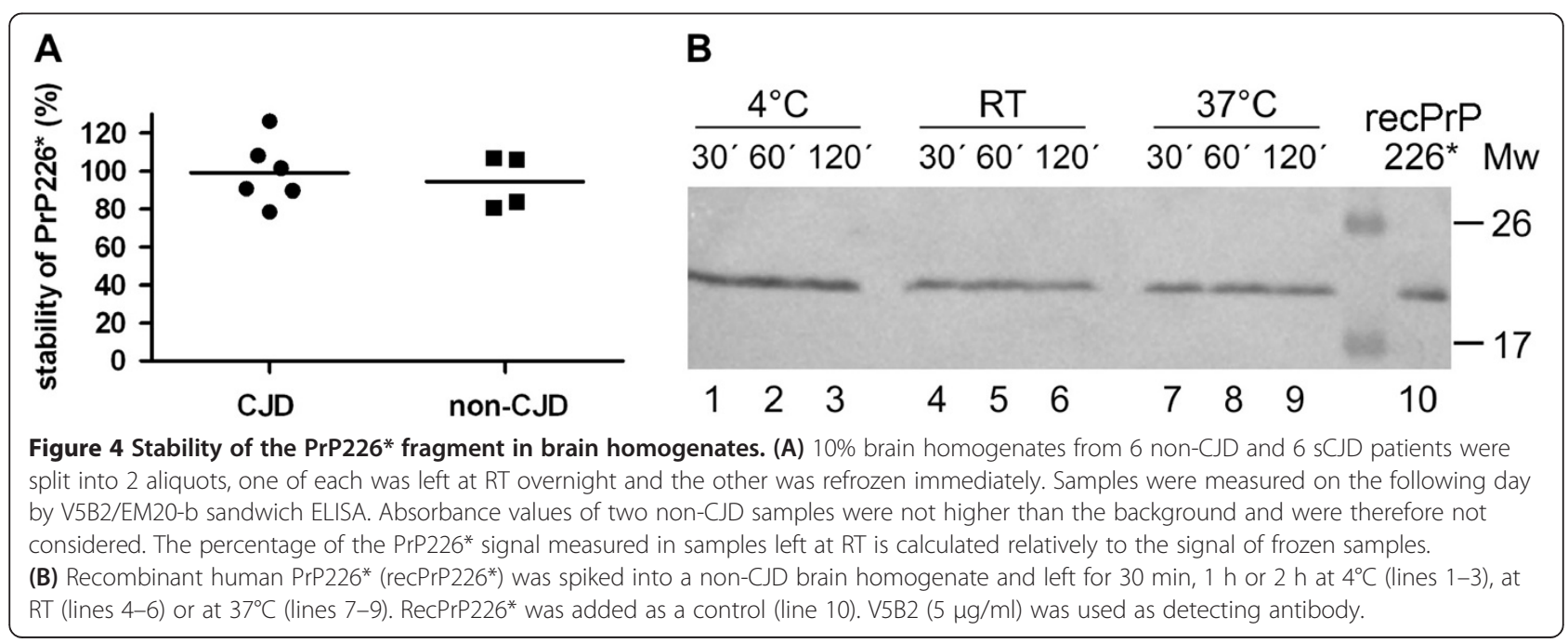




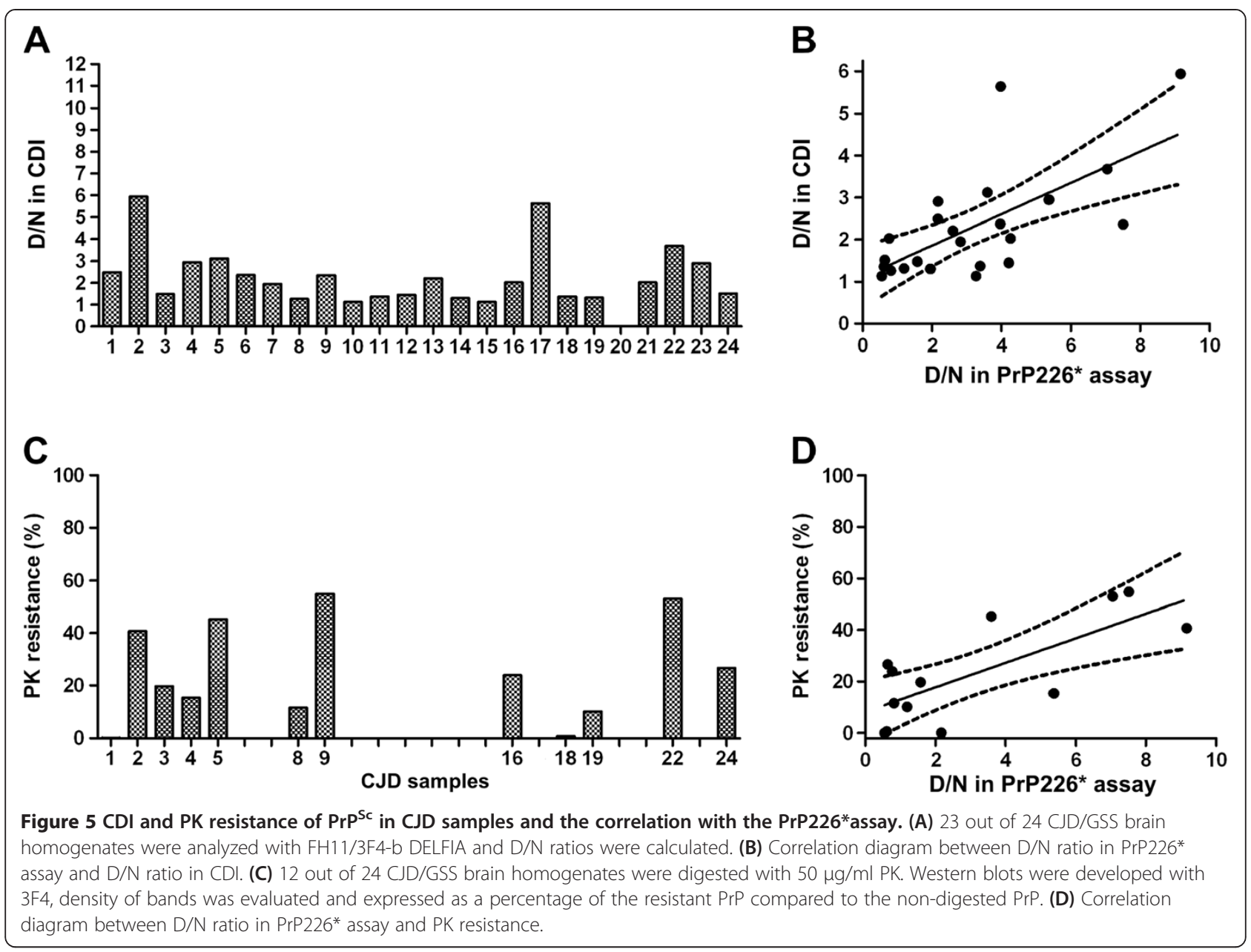

showed that standard PK treatment $\left(50 \mu \mathrm{g} / \mathrm{ml}, 37^{\circ} \mathrm{C}\right.$, $30 \mathrm{~min}$ ) led to substantial digestion of PrP in the majority of samples, however significant differences in the PrPres amount were detected between the individual samples. Values expressed as percentage of the PrPres signal as to the PrP signal in untreated samples, varied from 0-60\% (Figure 5C). When PrP226* $\mathrm{D} / \mathrm{N}$ ratio was compared to the percentage of PrPres in CJD/GSS samples, we found a correlation for all 12 values ( $\mathrm{P}$ value 0.0036 and Pearson correlation factor $r=0.7438$; Figure $5 \mathrm{D}$ ). These data indicate that samples with higher $\mathrm{PrP} 226 * \mathrm{D} / \mathrm{N}$ ratios are in general also more PK resistant.

\section{PrP226* correlation with standard CJD classifications}

To see whether the proportion of PrP226* in deposits (i.e. the $\mathrm{D} / \mathrm{N}$ ratio in $\mathrm{PrP} 226^{*}$ assay) correlates with standard CJD sample classifications, $\mathrm{D} / \mathrm{N}$ ratio measured by $\operatorname{PrP} 226^{*}$ assay was compared to the $\operatorname{PrP}{ }^{\mathrm{Sc}}$ type, to the Met/Val polymorphism at the codon 129 , to the presence or absence of 14-3-3 protein in the cerebrospinal fluid (CSF) and to the $\operatorname{PrP}^{\mathrm{Sc}}$ deposition pattern, determined by the immunohistochemical evaluation of
CJD/GSS samples. Our results demonstrate that the D/N ratio in $\mathrm{PrP}_{226 *}$ assay correlates neither with $\mathrm{PrP}^{\mathrm{Sc}}$ types nor with Met/Val polymorphism at the codon 129 (Figure 6A and B, respectively). We also found no correlation between $\mathrm{D} / \mathrm{N}$ ratio and the presence of 14-3-3 protein in the CSF (Figure 6C). Finally, IHC was performed on frontal cortex sections of nine chosen samples (samples 1, 4, 5, 8, 15, 16, 19, 22 and 24). The presence of plaques, as well as the morphology of depositions was evaluated but did not correlate with the $\mathrm{D} / \mathrm{N}$ ratio in PrP226* assay (Figure 6D). For more information on samples, see Additional file 2.

\section{Discussion}

In the present study, we developed a sandwich immunoassay for detecting glycosylphosphatidylinositol (GPI) anchorless PrP fragment ending with amino acid Y226, PrP226" [25]. The method is based on the use of monoclonal antibody V5B2 [24] and enables identification of the $\mathrm{PrP} 226 *$ fragment which is differently accessible in CJD and non-CJD brain tissue (Figure 1B). 

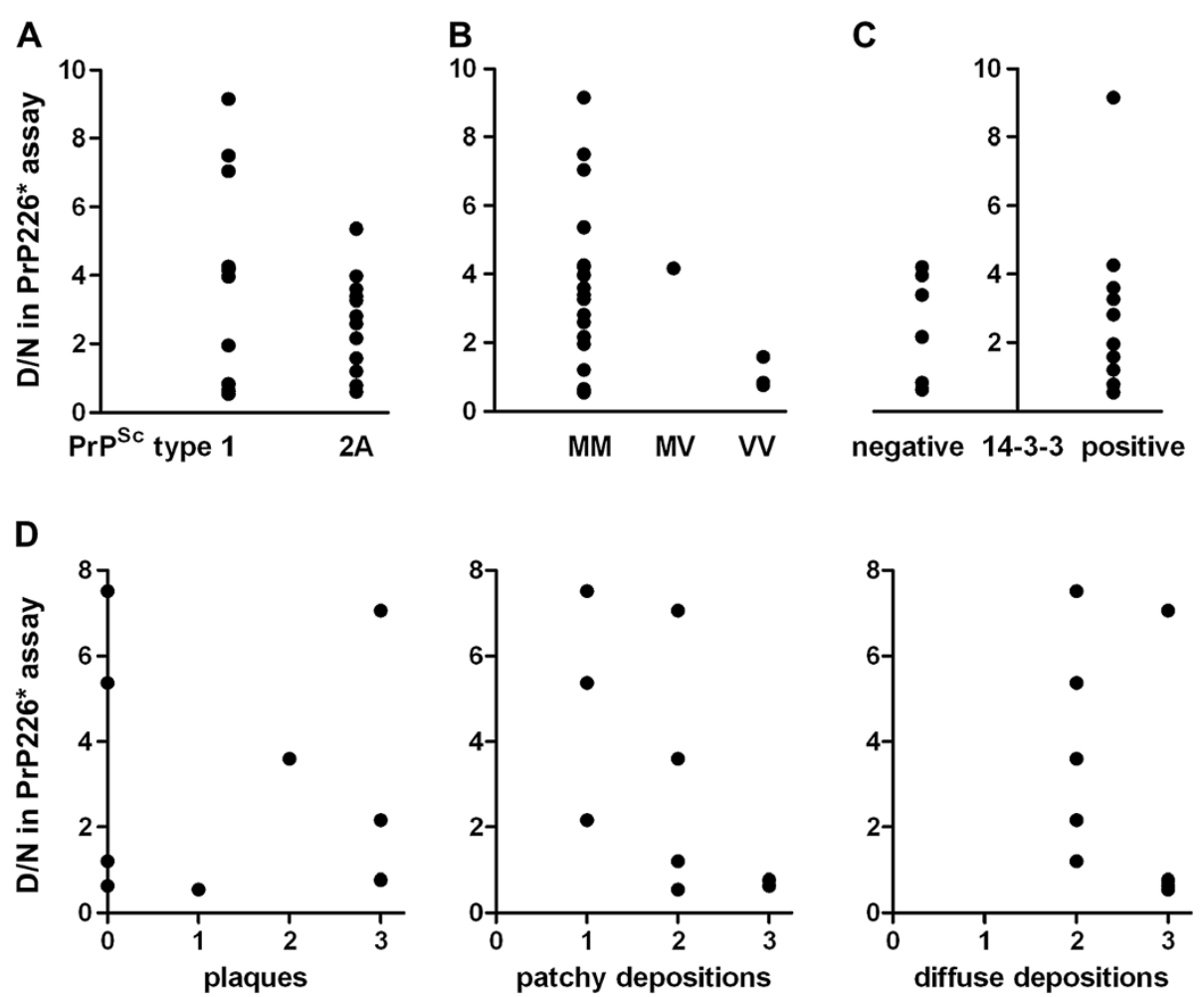

Figure 6 Correlation of D/N ratio in PrP226* assay with standard CJD classifications. The D/N ratio measured in V5B2/EM20-b DELFIA was compared (A) to the PrPSC type, (B) to the methionine (M)-valine ( $M$ polymorphism at the codon 129, (C) to the presence or absence of the 14-3-3 protein found in CSF and (D) to PrPSC deposition type evaluated by immunohistochemistry with $6 \mathrm{H} 4$ after PK cleavage of 9 CJD/GSS samples of frontal cortex. The intensity of prion plaques, patchy/perivacuolar depositions and diffuse/synaptic depositions were evaluated at the scale 0 to 3 . In all samples more than one deposition type was found. See also Additional file 2.

The PrP226* assay enables measuring $\mathrm{D} / \mathrm{N}$ ratio of PrP226* in a brain homogenate, i.e. the signal measured in a denatured sample, divided by the signal measured in the same sample under native conditions. Gdn-SCN-induced denaturation releases previously unavailable PrP226* from prion aggregates, therefore unmasking new V5B2 epitopes. The approach in PrP226* assay is based on similar principles as the Conformation-Dependent Immunoassay [26] and is exploiting chaotropic salts to unmask epitopes buried in prion aggregates. Chaotropic agents like Gdn-SCN, $\mathrm{Gdn}-\mathrm{HCl}$ or urea disrupt hydrogen bonds responsible for the secondary structure ( $\alpha$-helices and $\beta$-sheets) of proteins. Since hydrogen bonding also helps to maintain tertiary and quaternary structures of proteins, denaturation of human brain homogenates induced with Gdn-SCN (or $\mathrm{Gdn}-\mathrm{HCl}$ ), leads to dissociation of prion aggregates as well as to uncoiling of the PrP polypeptide chain.

Different brain tissue samples might need different denaturation conditions for the optimal dissociation of prion aggregates (Figure 2A). However 1.5 M Gdn-SCN was chosen for the $\mathrm{PrP226*}$ assay as a compromise to ensure the efficient denaturation of most of the samples.
We further optimized the dilution of samples after denaturation to assure that the final concentration of GdnSCN present on the microtiter plate affected minimally the binding capacity of V5B2 (Figure 2B). When recombinant PrP226* was used in the assay instead of brain homogenates, a $20 \%$ decrease of the signal was observed even when dilution of Gdn-SCN reached $0.075 \mathrm{M}$. The signal was further dropping rapidly upon the application of denaturant at final concentrations higher than $0.1 \mathrm{M}$, despite applying higher concentrations of recombinant PrP226* at the same time. The reason for the observed signal decrease could be the structural change of a part of V5B2 paratopes and its epitopes when exposed to denaturant.

The PrP226* assay takes advantage of the monoclonal antibody V5B2, directed against C-terminally truncated fragment of human prion protein that ends with the residue Y226. V5B2 is highly specific for all prion protein fragments ending with the AYY motif. Namely, deprivation of a single tyrosine as well as addition of a single amino acid to tyrosine 226 , would completely disrupt the V5B2 binding thus proving that the structure of the epitope at the PrP226* terminus is significantly different from the structure of the corresponding $\mathrm{C}$-terminal 
parts of fragments PrP225 or PrP227 or of the entire PrP [25]. These findings correspond very well to recent report of Jansen et al. on two patients with stop codon mutations in one allele of the PRNP gene, resulting in expression of either PrP225 or PrP226 (i.e. PrP226\%, [25]), apart from the normal, GPI-linked PrP. The two patients had strikingly different disease phenotypes, showing that the difference in the exposition of the tyrosine 226 may significantly affect the site of amyloid deposition and the overall phenotype of the prion disease [21].

The PrP226* assay was evaluated using 23 CJD, 1 GSS and 10 non-CJD human brain homogenates. We found that D/N values of PrP226* are lower than 0.7 for nonCJD brain and higher than 1.0 for $80 \%$ of CJD/GSS patients' brain (Figure 3). Moreover, we showed that $\mathrm{PrP}_{226 *}$ is relatively stable, meaning that only a minor part of it could be ascribed to the post-mortem or posthomogenization process of degradation by the released brain proteases (Figure 4A and B). Most of the PrP226* fragment is therefore present in the brain already at the time of death. Our study thus demonstrates that PrP226* accumulates in the prion protein deposits during the course of disease and could therefore serve as a biomarker for human TSEs.

We had the opportunity to also include a GSS sample in our study. This unusual GSS case was caused by a classical P102L mutation, but the manifestation of the disease resembled CJD [27]. The PrP226* assay showed a fivefold higher reaction for the denatured GSS sample, compared to the average signal of other brain homogenates tested (Figure 3C, sample 22), showing a greater abundance of the PrP226* fragment in GSS brain. Interestingly, Jansen et al. also described a GSS-like disease phenotype in a patient expressing PrP226* fragment due to a stop codon mutation on one PRNP allele [21].

To further elucidate the reason for $\mathrm{D} / \mathrm{N}$ ratio differences among the samples, included in our study, we measured the PK resistant fraction of $\operatorname{PrP}$ (PrPres) in the samples with either very high or very low $\mathrm{D} / \mathrm{N}$ (Figure $5 \mathrm{C}$ ). We found a general correlation between the proportion of PrP226* and PrPres in prion aggregates. However, it is worth stressing that we were able to clearly identify as positive one of the two CJD samples, which were completely degraded by $50 \mu \mathrm{g} / \mathrm{ml}$ PK (Figure $5 \mathrm{D}$, sample 1 ).

$\mathrm{D} / \mathrm{N}$ values obtained with the PrP226* assay, correlate with $\mathrm{D} / \mathrm{N}$ values measured by $\mathrm{CDI}$ assay, which implicates that the amount of $\mathrm{PrP} 226^{*}$ in aggregates is proportional to the amount of total misfolded PrP present in them (Figure 5A and B).

Fragments that might be related to the truncated PrP, PrP226*, have already been described in animal and human TSE affected brain. Stahl et al. showed that $15 \%$ of $\mathrm{PrP}^{\mathrm{Sc}}$ extracted from hamster brain was found to terminate at glycine 228 [14]. Although the site of cleavage of this fragment is different from that of PrP226*, the two fragments might originate from the same mechanism, but differ due to different amino acid sequence between hamster (mouse) and human PrP in the region of protease cleavage site. It is less likely that PrP226* originates in further proteolysis of the PrP228, as PrP226* has never been detected in mice (unpublished data).

Notari et al. identified two GPI-anchorless fragments in human CJD brain that migrate 2-3 $\mathrm{kDa}$ faster than PrPres (or PrP27-30) [13]. The fragments, which lack a few amino acids together with the GPI anchor at the very end of the $\mathrm{C}$ terminus, have an apparent molecular mass of about $18.5 \mathrm{kDa}$ when associated with PrP27-30 type 1 and of $17 \mathrm{kDa}$ when associated with type 2 . Notari et al. also identified a significant heterogeneity in the amount of these fragments among the tested CJD subtypes [13]. When we compared the $\mathrm{D} / \mathrm{N}$ ratio of PrP226*, measured in 24 CJD/GSS samples, to western blot profiles, to Met/Val polymorphism at the codon 129 , to the presence of 14-3-3 protein in CSF or to the type of $\operatorname{PrP}^{\mathrm{Sc}}$ depositions, we did not find a correlation with any of the mentioned parameters.

In the present study, we also demonstrated that PrP226* can be detected in the brain of some of the patients having no neurological disorders (Figure 3B). It is known that although the majority of the $\operatorname{PrP}^{\mathrm{C}}$ is bound to the cell membranes via a GPI anchor, a soluble form of $\mathrm{PrP}^{\mathrm{C}}$ is shed in a normal metabolic process from various cell types, e.g. neurons, splenocytes and platelets [28-30]. Anchorless $\operatorname{PrP}$, i.e. $\operatorname{PrP}(\Delta G P I)$, has also been identified in the medium of other cultured cells [31,32], in human cerebrospinal fluid and in serum [28,32]. The exact cleavage site on the PrP molecule has not been identified in these studies. Parkin et al. showed that apart from being removed by phospholipase $\mathrm{C}$ at serin 231 , a significant proportion of $\mathrm{PrP}^{\mathrm{C}}$ is shed from cell surfaces by the proteolytic action of a zinc metalloprotease which cleaves $\operatorname{PrP}^{\mathrm{C}}$ very close to the $\mathrm{C}$ terminus [15]. Whether the anchorless PrP226* originates in action of zinc metalloproteases and what might be its biological significance in healthy or diseased human brain remains to be determined.

\section{Conclusions}

The PrP226*assay is based on assessing differences between the levels of the soluble form of PrP226* and the PrP226*, packed in prion aggregates. Using this method we were able to show, that this anchorless PrP fragment is a part of prion aggregates in the brain of CJD/GSS patients. We also show that PrP226* can be detected in some non-CJD brains. The role of PrP226* in healthy brain and the importance of its involvement in the 
pathogenesis of human TSEs remains to be elucidated. However, the accumulation of PrP226* in prion deposits, shown in this study, and its toxicity when overexpressed [21], resembles the recent findings in mice where anchorless $\operatorname{PrP}$ was involved in $\mathrm{PrP}^{\mathrm{Sc}}$ formation [19] and, when overexpressed, also the sole cause of the disease $[20,33]$. The PrP226* assay, described in this paper, offers a tool to follow and study this anchorless PrP fragment in various parts of human brain and possibly also in other tissues and body fluids.

\section{Methods}

\section{Antibodies}

The following mouse monoclonal antibodies (mAbs) recognizing different epitopes in human PrP were used: V5B2, epitope 214-226 [24]; EM20, epitope in the region 121-231 (EXBIO Praha); FH11, epitope 51-54 (TSE resource centre, Rosslin Institute, Scottland); 3F4, epitope 109-112 (Covance); 6H4, epitope 144-152 (Prionics).

Conjugated antibodies were prepared by covalent labeling of primary antibodies with biotin using EZ-Link ${ }^{\odot}$ Sulfo-NHS-LC-Biotinylation Kit (Thermo Scientific). The dilutions of the conjugates used in the assays were optimized in titration assays to $0.5 \mu \mathrm{g} / \mathrm{ml}$ for both conjugates, biotinylated EM20 (EM20-b) and biotinylated 3F4 (3F4-b).

\section{Tissues}

The study was carried out on freshly frozen brain tissue samples of one GSS, $20 \mathrm{sCJD}$ and 3 fCJD patients. The study and its protocol were approved by the Central Ethics Committee of Thomayer Hospital and the Institute for Clinical and Experimental Medicine in Prague. In accordance with the guidelines of The Declaration of Helsinki informed consent was obtained either from patient or from relatives and all data were analyzed with respect to patient privacy.

CJD/GSS samples were previously confirmed by the National Reference Laboratory for TSE/CJD in Czech Republic. For negative controls we used freshly frozen brain tissue samples of 10 non-CJD cases without neurological disorders.

$\mathrm{PrP}^{\mathrm{Sc}}$ typing (according to the fragment size and glycoform ratio) and 14-3-3 determination were performed according to the standard procedures [34].

\section{Preparation of brain homogenates}

sCJD/GSS and non-CJD brain tissue samples were homogenized in 9 volumes of ice-cold lysis buffer $(0.5 \%$ Sodium deoxycholate, $0.5 \%$ Tergitol, $25 \mathrm{mM}$ Tris, $\mathrm{pH}$ 7.6) using a HT1000 Potter homogenizer. Brain tissue homogenates $(10 \%, \mathrm{w} / \mathrm{v})$ were not centrifuged, but aliquoted and stored at $-80^{\circ} \mathrm{C}$.

\section{V5B2/EM20-b sandwich ELISA}

NUNC MaxiSorp microtiter plates were coated with primary antibody V5B2 $(1 \mu \mathrm{g} / \mathrm{ml})$ in carbonate-bicarbonate buffer, $\mathrm{pH} 9.6$ and incubated overnight at $4^{\circ} \mathrm{C}$. Plates were than washed with the washing buffer $(0.05 \%$ Tween/PBS buffer, pH 7.2) and blocked with the blocking buffer (1\% BSA in washing buffer). Prepared native and denatured samples were further diluted $20 \mathrm{x}$ in the blocking buffer to final $0.25 \%$ brain homogenates. $50 \mu \mathrm{l}$ of samples were loaded and incubated for $90 \mathrm{~min}$ at $37^{\circ} \mathrm{C}$. Plates were washed and biotinylated antibody EM20-b $(0.5 \mu \mathrm{g} / \mathrm{ml})$, diluted in the blocking buffer, was added for $60 \mathrm{~min}$ at $37^{\circ} \mathrm{C}$. After washing, avidin-HRP was added (Pierce, 1:5000) for $30 \mathrm{~min}$ at $37^{\circ} \mathrm{C}$. After a final wash, TMB substrate solution (Pierce) was added. The reaction was stopped after $20 \mathrm{~min}$ by addition of $0.1 \mathrm{M} \mathrm{H}_{2} \mathrm{SO}_{4}$ and the absorbance was measured at $450 \mathrm{~nm}$.

\section{V5B2/EM20-b DELFIA (Dissociation-Enhanced Lanthanide} Fluorescent Immunoassay)

DELFIA was performed in the same way as sandwich ELISA until the addition of the biotinylated mAb, with the exception that PerkinElmer Wash Solution was used instead of washing buffer. After this step, plates were washed and further incubated for $30 \mathrm{~min}$ at $37^{\circ} \mathrm{C}$ with streptavidin-Eu (PerkinElmer), diluted to $0.125 \mu \mathrm{g} / \mathrm{ml}$ in Assay Buffer (PerkinElmer). After final washing, Enhancement solution (PerkinElmer) was added. Emission peaks were measured as time-resolved fluorescence at $613 \mathrm{~nm}$ from the top of the wells after excitation of the sample at $340 \mathrm{~nm}$, delay $400 \mu \mathrm{s}$.

\section{Stability of the PrP226* fragment}

The stability of PrP226*, inherently present in the brain, was measured in fresh brain homogenates of 6 CJD patients and 6 non-CJD individuals. Each homogenate was split in two aliquots, one was left at room temperature over night, while the other was immediately frozen and stored at $-80^{\circ} \mathrm{C}$ until measured. After samples denaturation, following the chosen protocol, the PrP226* was measured by V5B2/EM20-b ELISA, using $5 \mu \mathrm{g} / \mathrm{ml}$ of V5B2 (Figure 4A).

Next, we spiked recombinant PrP226* in $10 \%$ nonCJD brain homogenate (without the use of inhibitors) at concentration $1.5 \mu \mathrm{g} / \mathrm{ml}$. Aliquots were left at $4^{\circ} \mathrm{C}$, at $\mathrm{RT}$ or at $37^{\circ} \mathrm{C}$, respectively. From each aliquot samples were taken at different times (after $30 \mathrm{~min}, 60 \mathrm{~min}$ and $120 \mathrm{~min}$ ), immediately frozen at $-80^{\circ} \mathrm{C}$ and later loaded simultaneously to the SDS-PAGE gel. Final loading of recPrP226* was $5 \mathrm{ng} /$ well. Western blotting of the gel was performed with V5B2 $(5 \mu \mathrm{g} / \mathrm{ml})$ as detecting antibody, as described below (Figure 4B). 


\section{Optimization of denaturation of samples with guanidine thiocyanate}

Two 10\% sCJD brain homogenates were mixed with the same amount of stock solution of denaturant to reach increasing final concentrations (from $0 \mathrm{M}$ to $3 \mathrm{M}$ ) of guanidine thiocyanate (Gdn-SCN, prepared in $50 \mathrm{mM}$ Tris, $\mathrm{pH}$ 8) and incubated at $60^{\circ} \mathrm{C}$ for $15 \mathrm{~min}$. Samples were than 10 times diluted in $50 \mathrm{mM}$ Tris- $\mathrm{HCl}, \mathrm{pH} 8$, and the PrP226* fragment was measured by V5B2/ EM20-b ELISA. The plate was coated with $5 \mu \mathrm{g} / \mathrm{ml}$ of V5B2.

To test the denaturing effect of Gdn-SCN on coated antibody, recombinant human PrP226* at $100 \mu \mathrm{g} / \mathrm{ml}$ was divided into 2 aliquots. The first was treated 1:1 (v/v) with $3 \mathrm{M} \mathrm{Gdn}-\mathrm{SCN}$ at $60^{\circ} \mathrm{C}$ for $15 \mathrm{~min}$, than diluted $5 \mathrm{x}$ and further serially diluted with TBS-T. The second aliquot prepared without denaturant was diluted in the same way.

\section{PrP226* assay}

$10 \%$ brain homogenates were divided into 2 aliquots, the first was treated $1: 1(\mathrm{v} / \mathrm{v})$ with $3 \mathrm{M} \mathrm{Gdn}-\mathrm{SCN}$ at $60^{\circ} \mathrm{C}$ for $15 \mathrm{~min}$. The second aliquot was diluted with the same amount of $50 \mathrm{mM}$ Tris, $\mathrm{pH} 8$, and kept at RT. Both aliquots were further diluted 20x with TBS-T with $1 \%$ BSA (final concentration of the brain homogenate was $0.25 \%$ ) and applied to microtiter plates pre-coated with V5B2 $(1 \mu \mathrm{g} / \mathrm{ml})$. PrP226* fragment was detected by biotinylated EM20 $(0.5 \mu \mathrm{g} / \mathrm{ml})$.

\section{Conformation dependent immunoassays (CDI)}

CDI [26] was performed as a sandwich assay according to Bellon et al. [35], using FH11 $(1 \mu \mathrm{g} / \mathrm{ml})$ as the coating antibody and biotinylated antibody 3F4 $(0.5 \mu \mathrm{g} / \mathrm{ml})$ as detecting antibody, followed by the streptavidin-Eu (PerkinElmer) at concentration $0.125 \mu \mathrm{g} / \mathrm{ml}$. 10\% brain homogenates were denatured with $8 \mathrm{M} \mathrm{Gdn-HCl} \mathrm{(1:1} \mathrm{v/v)}$ and further diluted to a final concentration of $0.25 \%$ before application to the wells. DELFIA was performed as described above.

\section{Proteinase $\mathrm{K}$ digestion of samples}

For proteinase $\mathrm{K}(\mathrm{PK})$ digestion, brain homogenates were incubated with $50 \mu \mathrm{g} / \mathrm{ml}$ of $\mathrm{PK}$ at $37^{\circ} \mathrm{C}$ and after $30 \mathrm{~min}$ boiled in 5x SDS sample buffer (250 mM Tris, $\mathrm{pH} 6.8,10 \%$ SDS and 50\% glycerol) for $5 \mathrm{~min}$.

\section{Gel electrophoresis and Western blot analysis}

Prepared samples were resolved on $12 \%$ SDS polyacrylamide gels and proteins on the gels were blotted to nitrocellulose membranes as described previously [36]. For detection, monoclonal antibodies $6 \mathrm{H} 4(0.2 \mu \mathrm{g} / \mathrm{ml})$, 3F4 $(0.5 \mu \mathrm{g} / \mathrm{ml})$ or V5B2 $(5 \mu \mathrm{g} / \mathrm{ml})$ were used. For Western blots presented in Figure 1, HRP-conjugated goat anti-mouse IgG + IgM (JacksonImmunoresearch, $0.2 \mu \mathrm{g} / \mathrm{ml}$ ) was used, followed by the ECL detection. For all other western blots alkaline phosphatase-conjugated donkey anti-mouse IgG + IgM (JacksonImmunoresearch, $0.2 \mu \mathrm{g} / \mathrm{ml}$ ) was used, the reaction was visualized with BCIP substrate and the signal was quantified densitometrically by MiniLumi gel documentation system utilizing GelQuant densitometer software (DNR Bio-Imaging Systems Ltd.).

\section{Immunohistochemistry}

For IHC $5 \mu \mathrm{m}$ thick sections of formalin-fixed and paraffin-embedded tissue were used. Tissue slices were deparaffinized and washed in TBS. After that they were boiled in citrate buffer ( $\mathrm{pH} 7.6$ ) $3 \times 5 \mathrm{~min}$ in a microwave oven. Endogenous peroxidase was blocked with $0.05 \mathrm{mg}$ of natrium azide and $5 \mathrm{ml}$ of hydrogen peroxide in $50 \mathrm{ml}$ of distilled water. Non-specific positivity was blocked with $150 \mu \mathrm{l}$ of rabbit serum in $10 \mathrm{ml}$ of TBS for $30 \mathrm{~min}$. Before immunostaining, the sections were sequentially subjected to PK digestion $\left(10 \mu \mathrm{g} / \mathrm{ml}\right.$, at $25^{\circ} \mathrm{C}$ for $10 \mathrm{~min})$ and guanidine thiocyanate treatment $(2 \mathrm{M}$, at $25^{\circ} \mathrm{C}$ for $\left.30 \mathrm{~min}\right)$. The sections were incubated overnight at $4^{\circ} \mathrm{C}$ with $6 \mathrm{H} 4$ monoclonal antibody (1:2000, Prionics) diluted in 5\% fetal bovine serum in TBS. Detection of immunostaining was performed using Envision $^{\odot}$ kit with DAB chromogen. Specimens incubated with secondary antibody only and with nonspecific isotype-matched primary antibodies were used as a control of specificity. Mayer's haematoxilin was used as a nuclear counterstain.

\section{Additional files}

Additional file 1: Correlation between the $\mathrm{D} / \mathrm{N}$ ratio and the PrP226* quantity in denatured brain homogenates. The data from this correlation diagram were obtained by V5B2/EM20-b DELFIA. The values of denatured samples (D) are represented in counts per minute $(\mathrm{cpm})$. The line represents the slope of linear regression within the 95\% confidence interval.

Additional file 2: Characterization of samples by standard CJD classifications and by PrP226* assay. Samples are listed by number together with the result of the sample testing, performed in accordance with standard CJD classification procedures. An empty space in the table indicates that the test was not performed. In the last column the average PrP226* assay results are listed for each sample.

\section{Abbreviations}

-b: Biotinylated; CDI: Conformation-dependent immunoassay; CJD: Creutzfeldt-Jakob disease; sCJD: Sporadic Creutzfeldt-Jakob disease; CSF: Cerebrospinal fluid; DELFIA: Dissociation-enhanced lanthanide fluorescent immunoassay; D/N: Ratio between assay values for denatured and assay values for native samples; ELISA: Enzyme-linked immunosorbent assay; Gdn-HCl: Guanidine hydrochloride; Gdn-SCN: Guanidine thiocyanate; GPI: Glycosylphosphatidylinositol; GSS: Gerstmann-Sträussler-Scheinker disease; HRP: Horseradish peroxidase; IHC: Immunohistochemistry; mAb: Monoclonal antibody; PK: Proteinase K; PrP: Prion protein; $\mathrm{PrPC}^{\mathrm{C}}$ : Physiological isoform of the prion protein; $\operatorname{PrP}^{\mathrm{Sc}}$. Pathological isoform of the prion protein; PrP226*: Prion protein's fragment which ends with the 
amino acid 226 of the human prion protein sequence; PrPres: Proteinase K resistant core of the prion protein; PRNP: Prion protein gene; SDS-PAGE: Sodium dodecyl sulfate polyacrylamide gel electrophoresis; TBS-T: Mixture of TrisBuffered Saline and Tween 20; TMB: 3,3',5,5'-tetramethylbenzidine; TRF: Time resolved fluorescence; TSEs: Transmissible spongiform encephalopathies.

\section{Competing interests}

The authors declare that they have no competing interests.

\section{Authors' contributions}

ED carried out the experimental work, participated in the design of the study and drafted the manuscript. TV conceived the study, carried out the experimental work and drafted the manuscript. OJ conceived the study, carried out the experimental work and helped to draft the manuscript. MČ carried out the experimental work, participated in the design of the study and helped to draft the manuscript. SK performed western blots of human brain homogenates. AL participated in experimental work. RM carried out immunohistochemical studies. JN performed brain homogenates typing. $\mathrm{KH}$ and VČS participated in the design and coordination of the study and helped to draft the manuscript. All authors read and approved the final manuscript.

\section{Acknowledgements}

This work was supported by the Bilateral grant KONTAKT MEB 091004 from the Ministry of Education, Youth and Sports of the Czech Republic and BI-CZ /10-11-010 from the Slovenian Research Agency and grants IGA MZ NT14145-3 from the Czech Ministry of Health and L3-0206 from the Slovenian Research Agency. ED, OJ and KH were supported by programs of the Charles University in Prague: PRVOUK-P24/LF1/3, UNCE 204022 and SW-2013-266508.

We thank Professor Giuseppe Legname and his coworkers for their help in recombinant $\operatorname{PrP} 226^{*}$ preparation.

\section{Author details}

IInstitute of Immunology and Microbiology, 1st Faculty of Medicine, Charles University in Prague, Studnickova 7, 12820 Prague 2, Czech Republic. ${ }^{2}$ Department for Production of Diagnostic Reagents and Research, Blood Transfusion Centre of Slovenia, Šlajmerjeva 6, 1000 Ljubljana, Slovenia. ${ }^{3}$ Department of Pathology and Molecular Medicine, Thomayer Hospital, Vídeňská 800, 14059 Prague 4, Czech Republic. ${ }^{4}$ Current address: Institute of Macromolecular Chemistry v.v.i., AS CR, Heyrovsky square 2, 16200 Prague 6, Czech Republic. ${ }^{5}$ Current address: Omega, d.o.o., Dolinškova 8, 1000 Ljubljana, Slovenia.

Received: 21 November 2012 Accepted: 18 September 2013 Published: 25 September 2013

\section{References}

1. Prusiner SB: Novel proteinaceous infectious particles cause scrapie. Science 1982, 216:136-144.

2. Pan KM, Baldwin M, Nguyen J, Gasset M, Serban A, Groth D, Mehlhorn I, Huang Z, Fletterick RJ, Cohen FE: Conversion of alpha-helices into betasheets features in the formation of the scrapie prion proteins. Proc Natl Acad Sci USA 1993, 90:10962-10966.

3. Safar J, Roller PP, Gajdusek DC, Gibbs CJ Jr: Conformational transitions, dissociation, and unfolding of scrapie amyloid (prion) protein. J Biol Chem 1993, 268:20276-20284.

4. Parchi P, Capellari S, Chen SG, Petersen RB, Gambetti P, Kopp N, Brown P, Kitamoto T, Tateishi J, Giese A, Kretzschmar H: Typing prion isoforms. Nature 1997, 386:232-234.

5. Parchi P, Zou W, Wang W, Brown P, Capellari S, Ghetti B, Kopp N, SchulzSchaeffer WJ, Kretzschmar HA, Head MW, Ironside JW, Gambetti P, Chen SG: Genetic influence on the structural variations of the abnormal prion protein. Proc Natl Acad Sci USA 2000, 97:10168-10172.

6. Parchi P, Giese A, Capellari S, Brown P, Schulz-Schaeffer W, Windl O, Zerr I, Budka H, Kopp N, Piccardo P, Poser S, Rojiani A, Streichemberger N, Julien J, Vital C, Ghetti B, Gambetti P, Kretzschmar H: Classification of sporadic Creutzfeldt-Jakob disease based on molecular and phenotypic analysis of 300 subjects. Ann Neurol 1999, 46:224-233.
7. Collinge J, Sidle KC, Meads J, Ironside J, Hill AF: Molecular analysis of prion strain variation and the aetiology of "new variant" CJD. Nature 1996, 383:685-690.

8. Collinge J, Clarke AR: A general model of prion strains and their pathogenicity. Science 2007, 318:930-936

9. Piccardo P, Dlouhy SR, Lievens PM, Young K, Bird TD, Nochlin D, Dickson DW, Vinters HV, Zimmerman TR, Mackenzie IR, Kish SJ, Ang LC, De Carli C, Pocchiari M, Brown P, Gibbs CJ, Gajdusek DC, Bugiani O, Ironside J, Tagliavini F, Ghetti B: Phenotypic variability of Gerstmann-Straussler -Scheinker disease is associated with prion protein heterogeneity. J Neuropathol Exp Neurol 1998, 57:979-988.

10. Zou WQ, Capellari S, Parchi P, Sy MS, Gambetti P, Chen SG: Identification of novel proteinase K-resistant C-terminal fragments of PrP in CreutzfeldtJakob disease. J Biol Chem 2003, 278:40429-40436.

11. Zanusso G, Farinazzo A, Prelli F, Fiorini M, Gelati M, Ferrari S, Righetti PG, Rizzuto N, Frangione B, Monaco S: Identification of distinct N-terminal truncated forms of prion protein in different Creutzfeldt-Jakob disease subtypes. J Biol Chem 2004, 279:38936-38942.

12. Pan $T$, Li R, Kang SC, Pastore M, Wong BS, Ironside J, Gambetti P, Sy MS: Biochemical fingerprints of prion diseases: scrapie prion protein in human prion diseases that share prion genotype and type. J Neurochem 2005, 92:132-142.

13. Notari S, Strammiello R, Capellari S, Giese A, Cescatti M, Grassi J, Ghetti B, Langeveld JP, Zou WQ, Gambetti P, Kretzschmar HA, Parchi P: Characterization of truncated forms of abnormal prion protein in Creutzfeldt-Jakob disease. J Biol Chem 2008, 283:30557-30565.

14. Stahl N, Baldwin MA, Teplow DB, Hood L, Gibson BW, Burlingame AL, Prusiner SB: Structural studies of the scrapie prion protein using mass spectrometry and amino acid sequencing. Biochemistry 1993, 32:1991-2002

15. Parkin ET, Watt NT, Turner AJ, Hooper NM: Dual mechanisms for shedding of the cellular prion protein. J Biol Chem 2004, 279:11170-11178.

16. Kim Jl, Surewicz K, Gambetti P, Surewicz WK: The role of glycophosphatidylinositol anchor in the amplification of the scrapie isoform of prion protein in vitro. FEBS Lett 2009, 583:3671-3675.

17. Bate C, Tayebi M, Williams A: The glycosylphosphatidylinositol anchor is a major determinant of prion binding and replication. Biochem J 2010, 428:95-101.

18. McNally KL, Ward AE, Priola SA: Cells expressing anchorless prion protein are resistant to scrapie infection. J Virol 2009, 83:4469-4475.

19. Chesebro B, Trifilo M, Race R, Meade-White K, Teng C, LaCasse R, Raymond L, Favara C, Baron G, Priola S, Caughey B, Masliah E, Oldstone M: Anchorless prion protein results in infectious amyloid disease without clinical scrapie. Science 2005, 308:1435-1439.

20. Stöhr J, Watts JC, Legname G, Oehler A, Lemus A, Nguyen H-OB, Sussman J, Wille H, DeArmond SJ, Prusiner SB, Giles K: Spontaneous generation of anchorless prions in transgenic mice. Proc Natl Acad Sci USA 2011, 108:21223-21228.

21. Jansen C, Parchi P, Capellari S, Vermeij AJ, Corrado P, Baas F, Strammiello R, van Gool WA, van Swieten JC, Rozemuller AJ: Prion protein amyloidosis with divergent phenotype associated with two novel nonsense mutations in PRNP. Acta Neuropathol 2010, 119:189-197.

22. Risitano AM, Holada K, Chen G, Simak J, Vostal JG, Young NS, Maciejewski JP: CD34+ cells from paroxysmal nocturnal hemoglobinuria (PNH) patients are deficient in surface expression of cellular prion protein (PrPc). Exp Hematol 2003, 31:65-72.

23. Holada K, Simak J, Risitano AM, Maciejewski J, Young NS, Vostal JG: Activated platelets of patients with paroxysmal nocturnal hemoglobinuria express cellular prion protein. Blood 2002, 100:341-343.

24. Curin Serbec V, Bresjanac M, Popovic M, Pretnar Hartman K, Galvani V, Rupreht R, Cernilec M, Vranac T, Hafner I, Jerala R: Monoclonal antibody against a peptide of human prion protein discriminates between Creutzfeldt-Jacob's disease-affected and normal brain tissue. J Biol Chem 2004, 279:3694-3698.

25. Kosmac M, Koren S, Giachin G, Stoilova T, Gennaro R, Legname G, Serbec VC: Epitope mapping of a $\operatorname{PrP}(\mathrm{Sc})$-specific monoclonal antibody: identification of a novel C-terminally truncated prion fragment. Mol Immunol 2011, 48:746-750.

26. Safar J, Wille H, Itri V, Groth D, Serban H, Torchia M, Cohen FE, Prusiner SB: Eight prion strains have $\operatorname{PrP}(\mathrm{Sc})$ molecules with different conformations. Nat Med 1998, 4:1157-1165. 
27. Rusina R, Fiala J, Holada K, Matějčková M, Nováková J, Ampapa R, Koukolík F, Matěj R: Gerstmann-Sträussler-Scheinker syndrome with the P102L pathogenic mutation presenting as familial Creutzfeldt-Jakob disease: a case report and review of the literature. Neurocase 2012, 19:41-53.

28. Parizek P, Roeckl C, Weber J, Flechsig E, Aguzzi A, Raeber AJ: Similar turnover and shedding of the cellular prion protein in primary lymphoid and neuronal cells. J Biol Chem 2001, 276:44627-44632.

29. Hay B, Prusiner SB, Lingappa VR: Evidence for a secretory form of the cellular prion protein. Biochemistry 1987, 26:8110-8115.

30. Vostal JG, Holada K, Simak J: Expression of cellular prion protein on blood cells: potential functions in cell physiology and pathophysiology of transmissible spongiform encephalopathy diseases. Transfus Med Rev 2001, 15:268-281.

31. Harris DA, Huber MT, van Dijken P, Shyng SL, Chait BT, Wang R: Processing of a cellular prion protein: identification of $\mathrm{N}$ - and $\mathrm{C}$-terminal cleavage sites. Biochemistry 1993, 32:1009-1016.

32. Tagliavini F, Prelli F, Porro M, Salmona M, Bugiani O, Frangione B: A soluble form of prion protein in human cerebrospinal fluid: implications for prion-related encephalopathies. Biochem Biophys Res Commun 1992, 184:1398-1404.

33. Legname G, Baskakov IV, Nguyen HO, Riesner D, Cohen FE, DeArmond SJ, Prusiner SB: Synthetic mammalian prions. Science 2004, 305:673-676.

34. Zerr I, Kallenberg K, Summers DM, Romero C, Taratuto A, Heinemann U, Breithaupt M, Varges D, Meissner B, Ladogana A, Schuur M, Haik S, Collins SJ, Jansen GH, Stokin GB, Pimentel J, Hewer E, Collie D, Smith P, Roberts H, Brandel JP, van Duijn C, Pocchiari M, Begue C, Cras P, Will RG, Sanchez-Juan P: Updated clinical diagnostic criteria for sporadic Creutzfeldt-Jakob disease. Brain 2009, 132:2659-2668.

35. Bellon A, Seyfert-Brandt W, Lang W, Baron H, Gröner A, Vey M: Improved conformation-dependent immunoassay: suitability for human prion detection with enhanced sensitivity. J Gen Virol 2003, 84:1921-1925.

36. Brouckova A, Holada K: Cellular prion protein in blood platelets associates with both lipid rafts and the cytoskeleton. Thromb Haemost 2009, 102:966-974.

doi:10.1186/1471-2377-13-126

Cite this article as: Dvorakova et al:: Detection of the GPI-anchorless prion protein fragment PrP226* in human brain. BMC Neurology 2013 13:126.

\section{Submit your next manuscript to BioMed Central and take full advantage of:}

- Convenient online submission

- Thorough peer review

- No space constraints or color figure charges

- Immediate publication on acceptance

- Inclusion in PubMed, CAS, Scopus and Google Scholar

- Research which is freely available for redistribution 